\title{
ASPECTOS GEOTECTÔNICOS DA ÁFRICA OCIDENTAL A LESTE DO GOLFO DA GUINÉ COM REFERÊNCIA ÀS CONEXÕES ESTRUTURAIS E LITOLÓGICAS ENTRE BRASIL E ÁFRICA*
}

\author{
LOUIS DE LOCZY $\dagger$
}

\begin{abstract}
Based on the results of recent investigations in Western Africa, the author analyzes the geotectonic composition of Nigeria, Camerroon and Gabon, taking into consideration the structural, lithologic and geochronological relationships with those of the Brazilian margin in Pexnambuco and Sergipe. Advantage was taken of a reconnaissance journey made in January 1978, when the author visited the region of the "Volcanic Mountain" of the Republic of the Cameroon, the southern part of the "Ngaourandere Fault Zone" and the Cretaceous basins of Douala and the Niger delta. Of particular interest were the transcurrent alignments which fulfill an important role in the tectonic make up of the two continents. By way of comparison, the author also examined the geological framework of the Northeast and Northwest of Brazil and extended the general observations to the Brazilian Central-West as well as to the Guiana Shield. This work proposes to contribute to the clarification of some of the problems of the initial continental break-up and the separation of South America and Africa. Presented in this publication is a summary of the conclusions discussed in greater detal by the author in a previous work titled "Problemas Geotectônicos dos Alinhamentos Arqueozóicos do Cameroon, Pernambuco e Guaporé, com referência à mineralização de urânio"
\end{abstract}

GEOTECTONICA DA NIGERIA, CAMARÓES E GABÃo O núcleo antigo do Domínio "Camarðes-Gabão" representa um remanescente de rochas arqueozoicas da crosta afetadas, primeiramente, por deformaçzes e eventos de plutonização regional há mais de $2500 \mathrm{Ma}$. Durante a Orogênese Eburneana (2 100-1 $850 \mathrm{Ma})$, essas rochas sofreram intenso metamorfismo e remobilização. Na Nigéria, República dos Camaróes e o Pré-Cambriano Inferior está representado por vários núcleos constituídos por migmatitos e gnaisses afetados, ainda, por intrusð̃es graniticas. Nas regiбes da frontẹira República dos Camarōes-Gabão encontram-se grandes maciços graníticos, inclusive com granulitos e charnockitos, de idade radiogênica de aproximadamente $2800 \mathrm{Ma}$.

Desde a Orogênese Eburneana (equivalente ao Ciclo Transamazônico, no Brasil, as regiбes da Nigéria e da Republica dos Camarðes permaneceram estáveis. A zona do em. basamento do núcleo arqueozbico na Nigeria e na República dos Camaroes foi rejuvenescida por processos tectonotermais da "Orogênese Panafricana" (680-550 Ma.), durante o Pré-Cambriano Superior e o Eopaleozoico, com as intrusōes graníticas associadas. Uma nova reativação ocorreu durante a Reativação Wealdeniana (90.35 Ma), do final do Jurássico até o Terciário Inferior, que provocou intrusões hipoabissais.

Os granitos jovens (120.75 Ma), na Nigéria e na República dos Camarðes, ocorrem em ex tensão de $1500 \mathrm{~km}$, com uma largura média de $200 \mathrm{~km}$. Na região ao sul de Chade e Tibesti, assim como no Platô de Jos, essas intrusóes aparecem sob a forma de complexos anelares, controlados por falhas transcorrentes preexistentes (Fig. 1).

A feição tectônica mais importante desses terrenos é a presença de dois sistemas de falhamentos transcorrentes. Um com direção ENE-WSW, paralelo ao alinhamento de
Camarơes (Cameroon Trend), do tipo equatorial (dextrogiro), que pode ter formado o padrão estrutural inicial durante o Arqueano; e o outro, com direção NW-SE, de tipo submeridional (levogiro), do Proterozbico Inferior, que afetou principalmente as zonas pos-tectônicas do Pré-Cambriano Superior nas zonas costeiras.
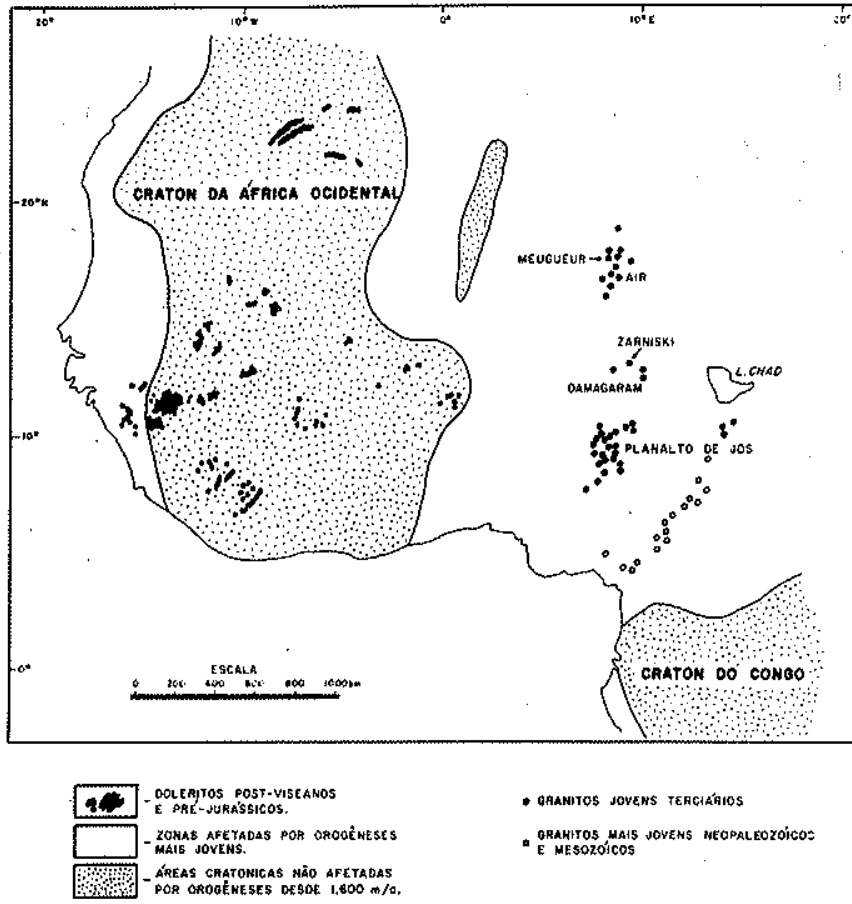

- ahanios jovers téciánios

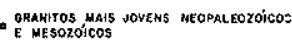

Figura 1 - Magmatismo paleozóico e mesozóico e os granitos mais jovens da Africa ocidental (Segundo Black \& Gi$\operatorname{rod} 1970)$ 
O alinhamento de camarões é uma ampla zona de fraqueza representando um extenso rift valley que corta $o$ continente africano, do Atlântico até o Saara (Líbia).

$\mathrm{Na}$ porção axial do alinhamento de camaröes, alinhase o sistema de falhas Ngaourandere, uma zona complexa, constituida por rochas do Pré-Cambriano Inferior. Corresponde a uma profunda linha de fraqueza que se estende para o norte até os Montes Mandaba. No sul está coberta pelas lavas do Monte Cameroon $(4.070 \mathrm{~m})$, de um vulcão ainda ativo (Fig. 2).
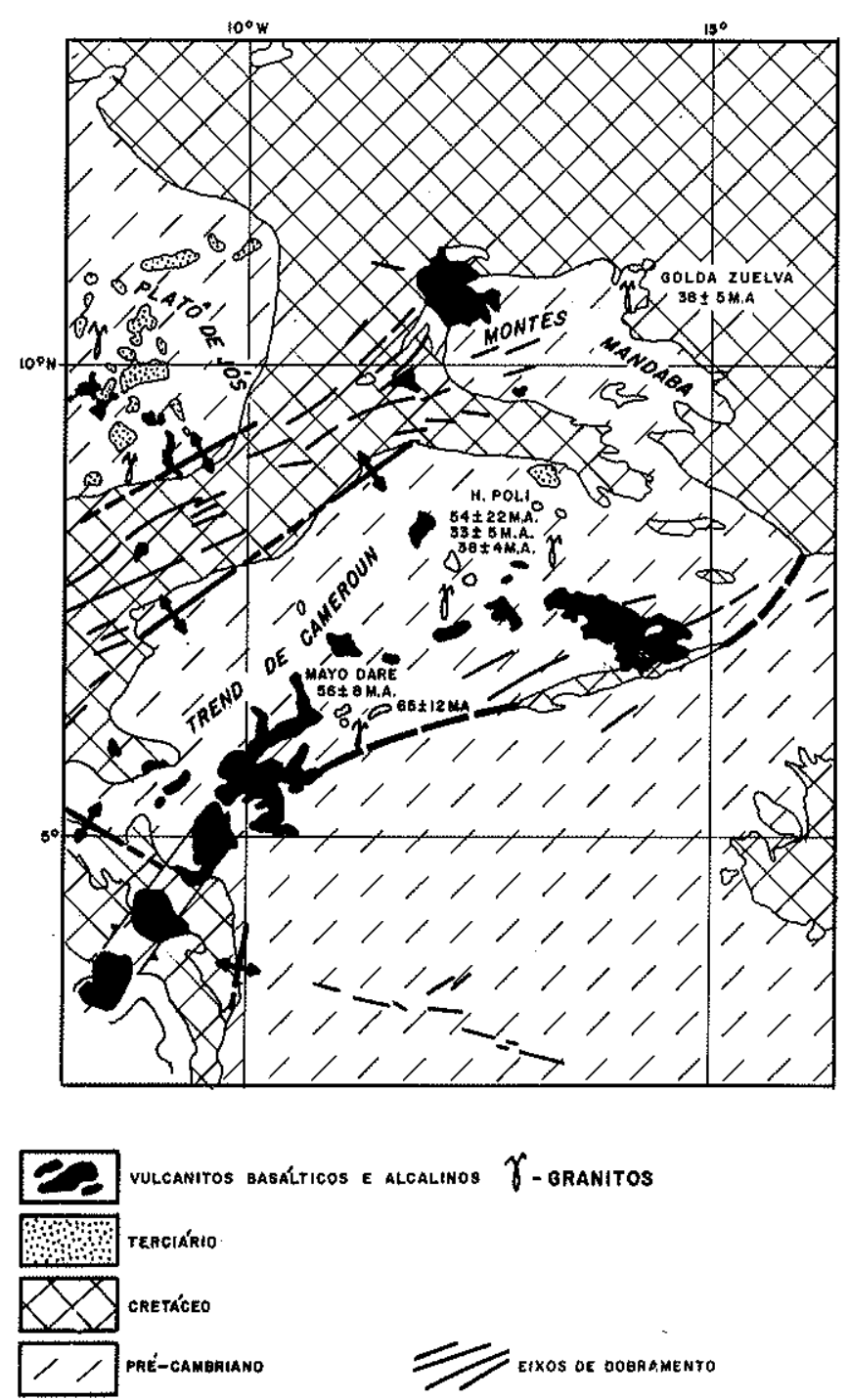

Figura 2 - Mapa geológico dos granitos terciários da Republica de Camaróes (idades radiométricas por Lasserre 1956)

A Zona de Falha Ngaourandere foi reativada durante o Eopaleozóico pela Orogênese Panafricana, acompanhada por intrusóes graniticas e, em seguida, novamente reativada durante o Mesozoico Superior, agora associada a um magmatismo complexo. A bacia sedimentar do Gráben Adanoua Sul e o vulcanismo são uma evidência desta reativação. Os granitos jovens, que freqüentemente formam diques anelares, têm idade radiogênica $8436 \mathrm{Ma}$. Na região central da República de Camaróes existem longas zonas milonitizadas que são similares à do Alinhamento de $\mathrm{Pa}$ tos e Pernambuco.
No Gabão, o Pré-Cambriano Inferior está representado pelos maciços de Chaillu e do Norte do Gabão, constituídos por migmatitos que foram afetados por intrusões graníticas. O Pré-Cambriano Médio está desenvolvido no Ga bão, bordejando o núcleo arqueano de Camarôs, ao longo de uma zona de subsidencia NW.SE. Formou-se uma bacia intracratônica com rochas sedimentares proterozoicas, predominantemente detríticas, pouco metamorfizadas, associadas a intrusôes básicas e vulcanitos ácidos. Es tas rochas sedimentares contêm as jazidas de urânio da Bacia de Franceville. O Pré-Cambriano Superior, no Gabão, consiste em sedimentos pelíticos, com tilitos, que não foram afetados pelas intrusర̃es básicas. As bacias marginais cretáceas do Golfo de Guiné são a Fossa do Benuê, Bacia do Delta do Niger e a Bacia de Douala, cujas origens estiveram tectonicamente relacionadas $a$ abertura do Oceano Atlântico.

A Fossa do Benué é um vasto gráben, preenchido por sedimentos cretáceos, com uma extensão de $800 \mathrm{~km}$ e largura média de $150 \mathrm{~km}$, que constitui uma feição estrutural linear que se prolonga até a Bacia do Chade. Está delimitada pelo Complexo Basal da Nigéria e contém sedimentos de idade albiana-santoniana, com uma espessura média de $6000 \mathrm{~m}$. Seu alinhamento é paralelo à direção ENE-WSW da linha costeira do Golfo de Guiné. A Bacia do Delta do Níger, localizada no flanco da Fossa do Benuê, na zona costeira, é constitulda de sedimentos cretáceos e terciários. A Bacia de Douala representa um meio-gráben preenchido por uma seqüência de sedimentos cretáceos com mais de $7000 \mathrm{~m}$ de espessura que repousam discordantemente sobre o embasamento cristalino (Fig. 3). As bacias cretáceo-terciárias costeiras do Gabão são fossas tectônicas intracontinentais, caracterizadas por sedimentos de água do. ce, semelhantes aos das Formaçoes equivalentes da Bacia do Recôncavo e da Bacia Sergipe-Alagoas.

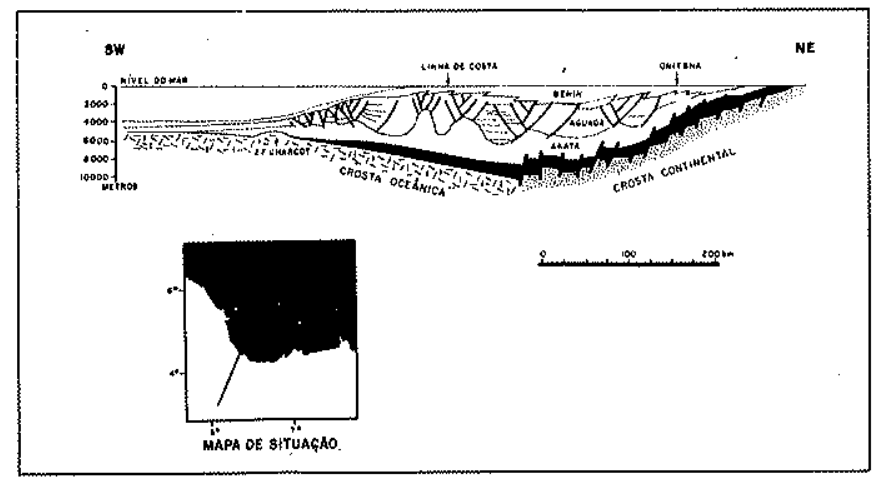

Figura 3 - Seção vertical esquemática do Delta do Niger (Delteil et al. 1975)

No Mesozoico e no Neozóico, subsistiram movimentos tectônicos numa larga zona costeira do noroeste da Åfrica. O rebaixamento e sedimentação nesta zona foram promovidos por movimentos verticais. Um bom exemplo é o Delta do Niger, onde os espessos sedimentos cretáceos e terciários repousam imediatamente sobre a crosta oceânica. Os alinhamentos das zonas de fratura oceânicas Chain e Charcott aproximam-se da costa e parecem prolongar-se pelo continente. $O$ alinhamento da Fossa cretácea do Benuê corresponde ao lineamento destas fraturas oceânicas. A sua sedimentaça e a estrutura diapítica, afetada 
por falhamentos de gravidade, são controladas pela fratura oceânica Charcott (Delteil et al. 1976). E notável que no Golfo da Guiné a Cadeia Meso-Atlântica avizinha-se da costa africana (Fig. 4).

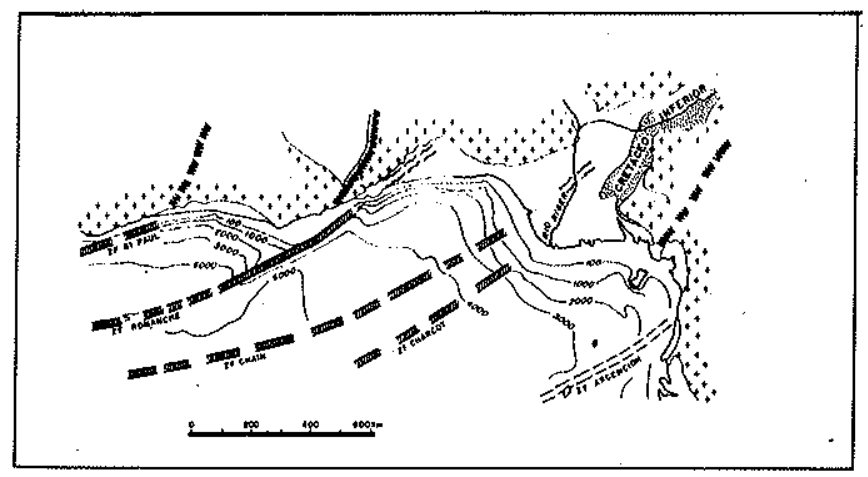

Figura 4 - Relações entre as zonas de fraturas equatoriais at lânticas e os alinhamentos estruturais continentais (Delteil et al. 1975)

Os geossinclíneos do Pré-Cambriano Superior do Escudo Brasileiro, alinhados principalmente NNE-SSW, faltam na Äfrica ou estão apenas secundariamente desenvolvidos ao longo das bordas dos crátons (Gabão). Os cinturóes PréCambrianos costeiros do nordeste da Åfrica sâo de caráter tafrogênico, afetados por atividade tectonotermal e por movimentos epirogênicos.

\section{GEOTECTONICA DO ALTO PERNAMBUCO-ALAGOAS}

O Alinhamento de Pernambuco representa uma estrutura transversal, orientada $\mathrm{E}-\mathrm{W}$, que interrompe as estruturas NNE-SSW, predominantes nos blocos pré-cambrianos no leste e nordeste do Brasil. As profundas falhas transcorrentes, com rejeito diferencial E-W, têm um papel importante na constituição tectônica do grande acidente estrutural que corresponde ao Alinhamento de Pemambuco. As falhas de Patos e de Pernambuco sto profundas geossuturas do tipo equatorial, cujo aparecimento precedeu os ciclos orogê. nicos Transamazônico e Brasiliano, mas que foram reativadas, repetidamente, durante aqueles ciclos e mesmo no Wealdeniano. As falhas Patos-Pernambuco, Paulistana-Floresta e Arcoverde sáo marcadas no terreno por faixas de catacasitos e milonitos, evidenciando intenso cisalhamento (Fig. 5).

Segundo conceito do autor, essas falhas transcorrentes parecem ser manifestaçðes de um alinhamento primordial, este-oeste, do antigo domínio cratônico do embasamento arqueozóico, semelhante aos alinhamentos aproximadamente este-oeste das formaçōes arqueozóicas do Cráton das Guianas e do Cráton do Guaporé.

Nesta área, as exposiçðes do embasamento são relativamente raras, pois, na maior parte das vezes, acham-se ocultas sob os metassedimentos brasilianos. Segundo Brițo Neves \& Cordani (1973), o Alto Tectônico Pemambuco-Alagoas representa um antigo maciço granítico-migmatítico, de possível idade transamazônica (2000 Ma) reativado em épocas posteriores, especialmente no Brasiliano.

O Maciço do Alto Pernambuco-Alagoas, por sua litologia complexa, granítico-migmatítica com granulitos, e pelo seu comportamento tectônico, deveria ser equivalente ao $\mathrm{Ma}$ ciço de Chaillu e ao Maciço de Camarôes.. Apesar de ainda não estar provada por dataçðes geocronológicas, a presença de rochas arqueozóicas, a ocorrência de cordierita granulitos perto de Arapiraca, na área do Maciço Itatiba, devem ser o testemunho de que o embasamento do Alto PernambucoAlagoas seja constituído por rochas arqueozóicas remobilizadas em épocas posteriores, durante os ciclos Transamazônico, Uruaçuano e Brasiliano (Fig. 5).

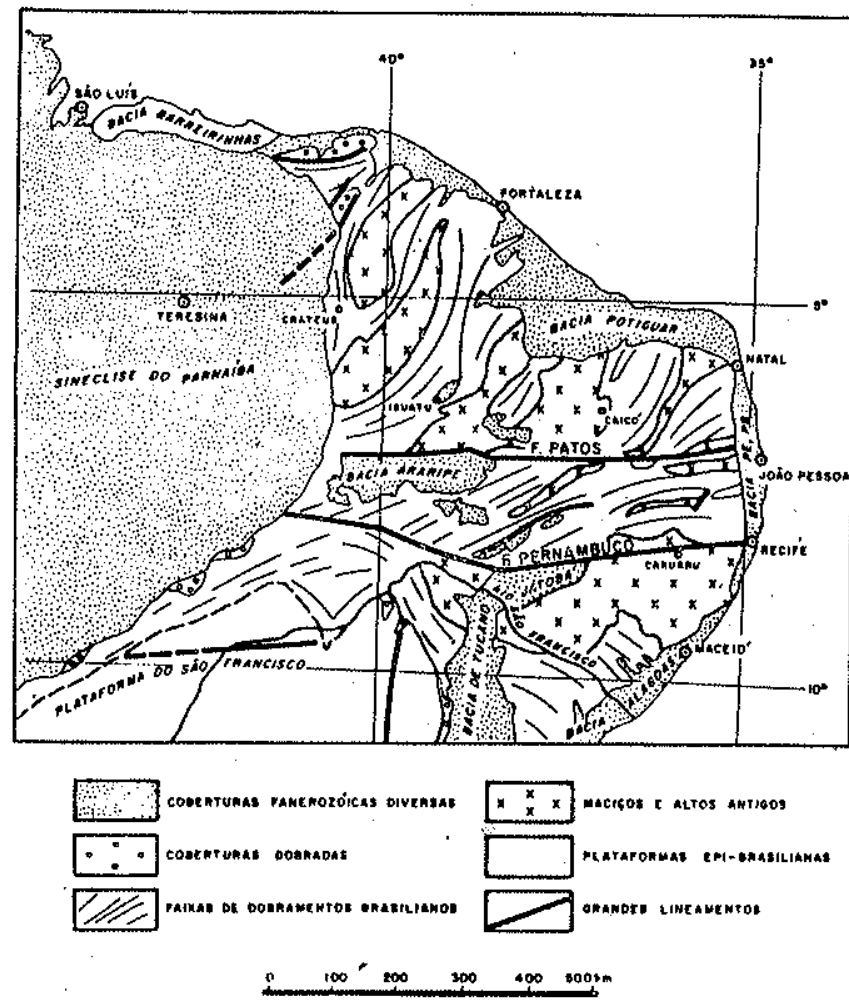

Figura 5 - Esquema geologico do Nordeste

Uma reativação pós-tectônica ocorreu durante o Ciclo Brasiliano tardio (Taconiano, $500 \mathrm{Ma}$ ), originando as intrusões de granitos alcalinos associados à Falha de Patos. No sul de Alagoas, esses granitos e granodioritos pós-tectônicos são acompanhados por faixas cataclásticas e miloníticas.

Manifestaçőes representativas da Reativação Wealdeniana foram o plutonismo e o vulcanismo, de idade cretácea, no Cabo Santo Agostinho, os quais geraram a única ocorrência de granitos cretáceos (90 Ma) em todo o Brasil.

CONTINUIDADE DOS ALINHAMENTOS DE CAMARÓES E DE PERNAMBUCO As evidências que provam que os alinhamentos de Camaróes e de Pernambuco são feiçőes estruturais contínuas, de origem comum, que já existiam quando os dois continentes ainda estavam unidos são: 1) essas linhas estruturais atingem perpendicularmente a linha da costa atlântica no Brasil e na África; o Alinhamento de Camarőes continua no oceano sem mudança do seu caráter tectônico e direção; a fratura oceânica de Ascensão parece afetar a ligação com o Alinhamento de Pernambuco (Gorini et al. 1976); 2) similaridade no tectonismo dos sistemas de falhas transcorrentes de Ngaourandere e de Pernambuco e suas reativaçóes durante o Eopaleozóico e Mesozóico Superior, associadas a vulcanismo e plutonismo; 3) uma evidência de grande importância, quase decisiva: as intrusōes graníticas hiperabissais de idade 
cretácea, que são tão extensas na África Equatorial, no Brasil ocorrem somente no Cabo (Pernambuco).

\section{PROVAS DE ROMPIMENTO PRECOCE DO CONTINEN-} TE ANTES DA DERIVA CONTINENTAL Apesar de não haver dúvida de que os alinhamentos de Camarōes e de Pernambuco são feições estruturais contínuas, de origem comum, ainda assim eles são interrompidos e divididos por um espaço vazio, que deveria incluir a zona de transição entre a Faixa Orogênica Brasiliana e a faixa tafrogênica contemporânea na África Ocidental (Nigéria e República dos Camaroes). No caso da Zona de Falha Ngaourandere e da Zona de Falha Pernambuco, a continuidade estrutural não é perfeita. Também neste caso falta uma transição entre as duas zonas. Entretanto, não é provável que durante o Pré-Cambriano Superior tenha existido uma delimitação brusca entre a faixa orogênica e a faixa tafrogênica, no continente ainda unido.

A presença de granulitos e charnockitos no Maciço de Pernambuco-Alagoas, semelhantes aos do Maciço Chaillu, no Gabão, representa também um forte argumento relativo ao rompimento precoce do continente (Fig. 6).
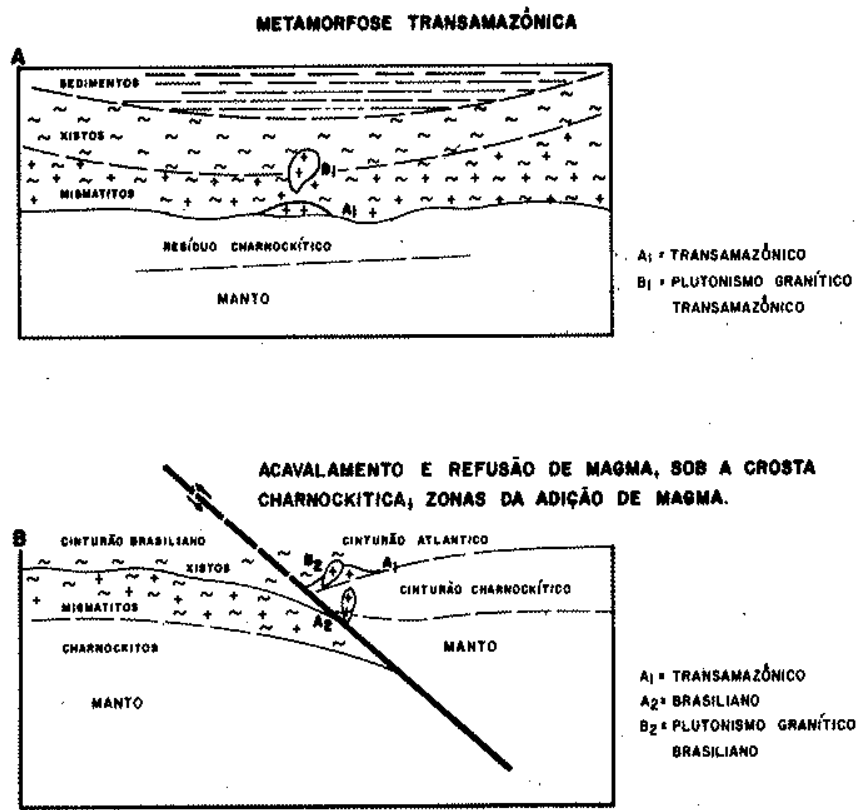

Figura 6 - Evolução esquemática da Zona Atlantica (segundo Leonardos Jr. et al. 1976)

Segundo o conceito de Leonardos Jr. et al. (1976), a presença de antigas rochas granulíticas e charnockíticas, formadas por ultrametamorfismo e fusão, em consequiência de acavalamento dos blocos continentais, indica que as faixas pré-cambrianas marginais do Brasil, entre o Rio de Janeiro e a Bahia, deveriam existir mesmo antes de um bilhão de anos. A carreação panafricana parece ter um papel importante na evolução crustal da margem continental do Brasil. A colisão continental, associada com magmatismo e formação de nappes, produzira a fácies granulítica dos cinturôes marginais brasileiros (Fig. 7).

O cinturăo granulítico, entre o Rio de Janeiro e Pernam buco-Alagoas, parece suportar uma boa evidência para a validade da teoria de Leonardos Jr. et al. (op. cit.); mostra que o rompimento e a colisão continental precoce não constituíram somente um episódio isolado, mas, sim, um acontecimento regional, extensivo a toda a costa atlântica do Escudo Brasileiro (Fig. 8).

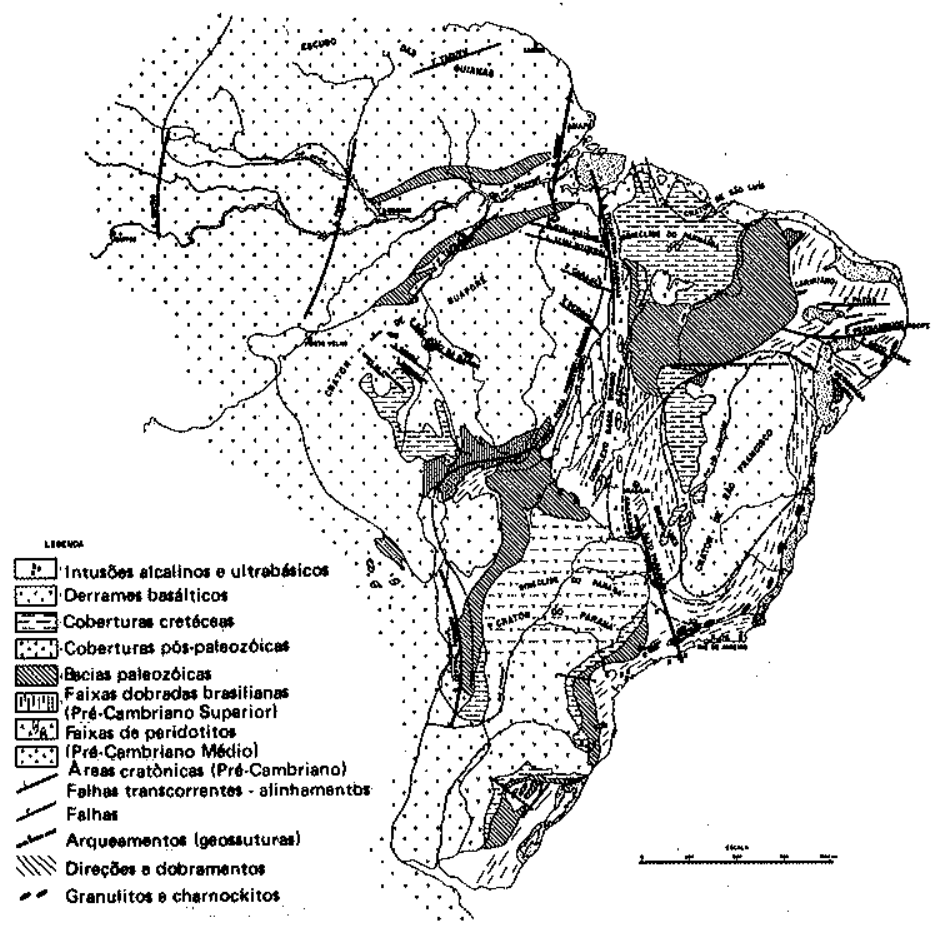

Figura 7 - Mapa geotectónico do Noroeste e Nordeste do Brasil

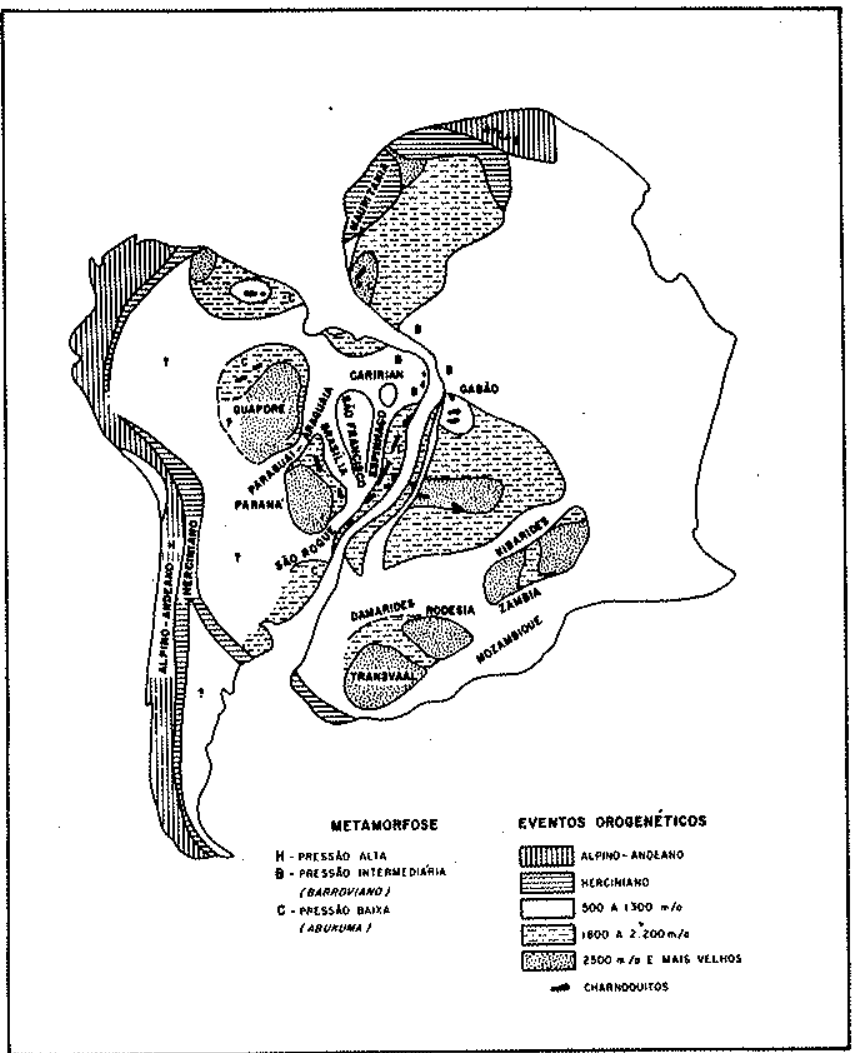

Figura 8 - Relaçôes estruturais entre Africa e Brasil (segundo Leonardos Jr. \& Fyfe 1974; Choubert 1968, e Clifford 1970) 
CONEXÓES E LIGAÇÕES CONTINENTAIS Vários autores, comparando as feiçбes geológicas do nordeste do Brasil com as do noroeste da África e, baseados na similaridade estratigráfica, litológica e geocronológica, postularam conexđ̋es e ligaçð̋es pretéritas. Porém, confrontandose as zonas costeiras pré-cambrianas do Brasil com as da África, constata-se que, do ponto de vista tectônico, em nenhum lugar existe uma ligação imediata entre os respectivos lineamentos, uma vez que as feições orogênicas da costa do Brasil, fortemente remobilizadas e metamorfizadas, não podem ser correlacionadas com as feiçбes tafrogênicas da costa da África, as quais são afe tadas por processos tectonotermais e por movimentos epirogenicos.

Entre as feiçőes dobradas e falhadas, ainda falta uma extensa zona de transição, que parece corresponder à $\mathrm{Ca}$ deia Meso-Atlântica que, nesse caso, já existiria desde o Pré-Cambriano. A zona de transição encontra-se, talvez, no lado oeste da Cadeia Meso-Attântica, cuja origem poderia ser explicada por meio de colisáo e acavalamento de placas continentais profundas que produziram as faixas orogênicas remobilizadas da costa brasileira (Fig. 6).

PROBLEMA DA CADEIA MESO-ATLÁNTICA Neste ponto é oportuno levantar-se a questão: representa, na verdade, a Cadeia Meso-Atlântica uma feição estrutural de idade mesozóica superior relacionada a um único evento, em conseqüência da deriva dos continentes da Ãfrica e da América do Sul?

Os rompimentos anteriores dos continentes, acima descritos, permitem supor que a Cadeia Meso-Atlântica deveria existir ainda antes da separação da África e da América do Sul. E provável que a translação dos dois continentes tenha começado a se processar já no Pré-Cambriano Medio, nos ciclos anteriores à regeneração do oceano. Deste modo, pode-se postular a persistência da Cadeia Meso-Atlântica, que teria sempre mantido sua posição mediana entre os dois continentes. A história do Oceano Atlântico demonstra que um primeiro rompimento do continente aconteceu, provavelmente, logo em seguida à Orogênese Transamazô. nica, no Proterozóico Médio; e um segundo, no fim da Orogênese Brasiliana. No Cambro-ordoviciano já deveria existir uma estreita zona oceânica no noroeste e no sudoeste da África (Figs. 9 e 10) (Loczy 1970, 1972).

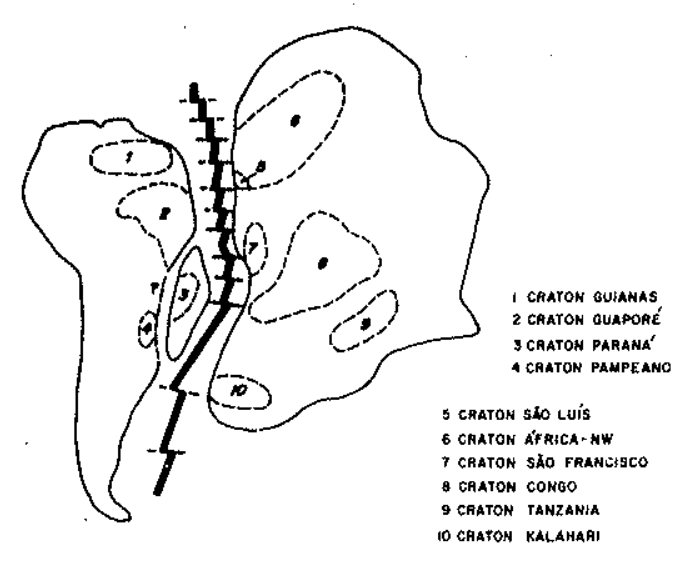

Figura 9 - Atlántico Sul pré-Brasiliano. Pressuposta aber. tura do Oceano Atlântico precoce

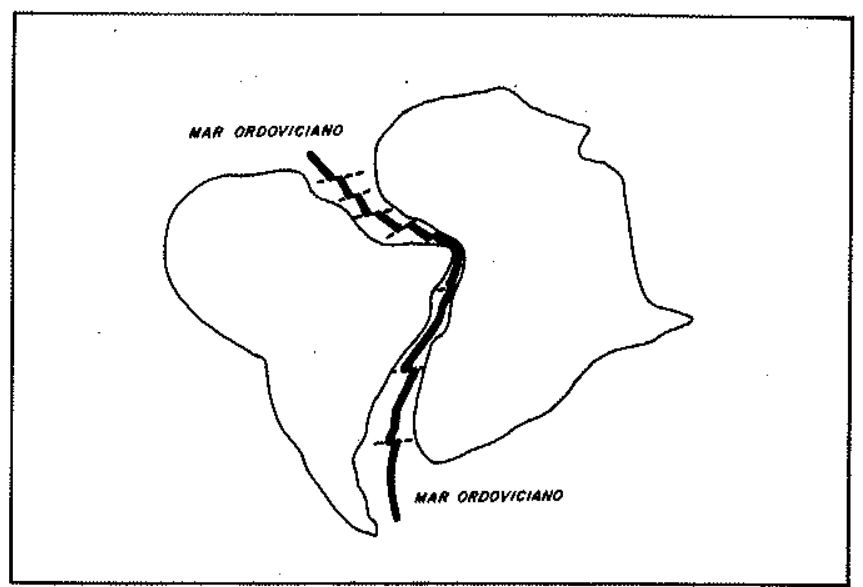

Figura 10 - Atlântico Sul pós-Brasiliano

ENSAIO DE INTERPRETAÇÅO DA GENESE DA FOSSA DOS GEOSSINCLINAIS DO PRE-CAMBRIANO MEDIO E SUPERIOR DO ESCUDO BRASILEIRO O autor analisou a constituição macrotectônica dos dois continentes com o objetivo de procurar esclarecer a origem da ampla fossa dos geossinclinais do Pré-Cambriano Médio e Superior do Escudo Brasileiro e o seu estranho alinhamento submeridional NNE-SSW, divergente do alinhamento predominante, dex trógiro, E-W, dos escudos da África, das Guianas e, memo, do Cráton de Guaporé (Fig. 7). Levanta-se, ainda, a questão de se esta ampla fossa representa um rift-valley intercratônico originado por movimentos verticais controlados por profundas falhas transcorrentes com orientação NNE-SSW, ou se ela ter-se-ia originado pelo rompimento do continente e abertura de uma profunda fenda oceanica, associada d̀ ascensão do magma básico e ultrabásico, cuja idade radiogênica está entre $3067 \mathrm{Ma}$. e $1100 \mathrm{Ma}$. (Fig. 9).

Uma parte dos maciços básicos e ultrabásicos, sobretudo peridotiticos, dispre-se ao longo de cerca de $700 \mathrm{~km}$, com direção N-S, no eixo mediano do Complexo Basal Goiano, formando uma nitida estrutura linear do tipo Alpino (Fig. 7). 0 magmatismo ultrabásico de idade cretácea, que se manifesta por chaminés circulares no Arco Alto Parnarba e no Arco Tocantins-Araguaia, parece estar geneticamente ligado, por rejuvenescimento, aos maciços básico-ultrabásicos do Complexo Basal Goiano. A presença de cinturóes magmáticos rejuvenescidos parece indicar uma distribuição regional, contínua, da antiga cadeia de peridotitos ao longo de uma fenda oceânica formada entre o Amapá e o Rio de Janeiro, cortando o Bloco Brasileiro (Fig. 7). Durante - Ciclo Transamazônico, a fenda oceânica fechou-se em conseqüência dos movimentos de compressão. $\mathrm{O}$ melhor argumento para este conceito hipotético é o alinhamento meridional N-S das feiçðes estruturais, paralelas às da grande cordilheira da Cadeia Meso-Atlântica precoce.

\section{CONEXAO DO EMBASAMENTO ARCAICO DE PER-} NAMBUCO-ALAGOAS E DO CRATON DE GUAPORE $O$ embasamento antigo do Alto Tectônico PernambucoAlagoas, sem dúvida, continua no Cráton de Guaporé, interrompido pela sinéclise paleozóica-mesozóica do Parnaíba e pelo Arco Tocantins-Araguaia. $O$ alinhamento tectônico, representado pelas falhas transcorrentes de tipo equatorial (dextrógiras) do Cráton de Guaporé, tem direção 
WNW-ESE e E-W, correspondendo aos alinhamentos similares dos territorios pernambucano e sergipano (Silva et al. 1974, Issler 1977). As falhas transcorrentes Carajás e Seringa, a leste, bem como as falhas São João da Barra, Canamá e Dardanelos, a oeste do Cráton de Guaporé, são orientadas WNW-ESES e E-W e parecem.ter conexão com as falhas transcorrentes Pernambuco e Arcoverde (Fig. 5). 0 embasamento arqueozóico do Cráton de Guaporé é constiturdo pelo Complexo Xingu, que engloba granitos, granulitos e gnaisses cobertos pelas rochas proterozoicas dos grupos Beneficente e Uatumã. No entanto, os alinhamentos dextrógiros do Cráton de Guaporé, a leste, estão truncados pela geossutura submeridional, N-S, Tocantins-Araguaia, de idade pós-transamazônica, que se encontra na borda oriental daquele craton (Almeida 1974, Choubert 1969). Por esta razão o alinhamento dextrógiro Pernambuco-Gua poré e a conexão entre os dois crátons estão interrompidos, provavelmente pelo rompimento do continente e formação de uma fenda oceânica alinhada N-S, que deu lugar aos geossinclineos brasilianos (Fig. 7).

\section{PERSPECTIVAS DA PROSPECCAO DE URANIO EM PERNAMBUCO.ARCOVERDE Os conhecimentos geo-} logicos concernentes aos importantes depositos de urânio do Geossinclíneo de Franceville (Gabão) poderiam fornecer informaçôes valiosas para a prospecção de urânio nas áreas pré-cambrianas do nordeste do Brasil, especialmente no Alto Tectônico Pernambuco-Alagoas e regiøes adjacentes (Fig. 5).

As rochas uranfferas da Bacia de Franceville podem ser comparadas com as rochas arenosas e carbonáticas que formam o manto sedimentar que bordeja o núcleo migmatítico-granitóide do Maciço de Itaŕba, em Arcoverde. $O$ Quartzito Itabaiana representa a unidade transgressiva basal do pacote sedimentar. Sobrepóe-se a uma espessa seqüência de $x$ istos com calcários que domina na parte norte Alagoas - mas falta na parte sul - Sergipe (Santos 1971). As rochas arenosas e carbonáticas que margeiam o Maciço de Itaíba podem ser identificadas com os metassedimentos terrígenos do Grupo Caico, constituído por metarcoseos, micaxistos, migmatitos e quartzitos do Geossinclíneos Serido, onde numerosas anomalias uraniferas foram detectadas. Já foram realizados trabalhos de prospeç̧ão que devem ser retomados no futuro (Loczy 1977). Os grupos Caicb e Serido ocorrem também na zona do Lineamento de Patos, em Pernambuco, onde as anomalias radiogênicas parecem ser promissoras.

Os conglomerados oligomíticos uraniferos do Protero. zoico Inferior, que repousam imediatamente sobre o escudo arqueozbico, são geralmente considerados como importante indicador do tempo geológico, oferecendo um excelente guia para a prospeç̧ão de urânio em todo o mundo. Mineralizaçסes uraniferas em metassedimentos terrígenos do Proterozóico Inferior poderiam ocorrer tambem no Cráton de Guaporé, onde, sobre o escudo arqueozbico do Complexo Xingu, repousam, discordantemente, os epimetamorfitos proterozóicos do Grupo Beneficente, constituido por quartzitos e ortoquartzitos superpostos por pelitos com ardósias e folhelhos. O Grupo Beneficente aflora numa faixa contínua, especialmente na area situada entre os rios AripuanaJuruena-Teles Pires (Issler 1977).

\section{REFERENCIAS BIBLIOGRAFICAS}

ALMEIDA, F.F.M. de - 1967 - Origem e evolução da Plataforma Brasileira. Rio de Janeiro, DNPM/DGM. (Boletim 241).

ALMEIDA, F.F.M. de - 1974 - Sistema tectônico marginal do Cráton de Guaporé. In: CONGR. BRAS. GEOL., 28, Porto Alogre, 1974. Anais. . Porto Alegre, SBG, v. 4, p. 9-17.

BLACK, R. \& GIROD, M. - 1970 - Late Paleozoic to recent igneous activity in West Africa and its relationship to basement structure. In: OLIVER AND BOYD. African Magmatism and Tectonism, s.e., p. 185-210.

BRITO NEVES, B.B. - 1973 - Elementos da geologia pré-cambriana do Nordeste Oriental. In: CONGR. BRAS. GEOL., 27, Aracaju, 1973. Anats. .. Aracaju, SBG, v. 2, p. 105-134.

BRITO NEVES, B.B.; SIAL, A.N.; ALBUQUERQUE, J.P. - 1977 Vergência centrífuga residual no Sistema de Dobramento Sexgipano. Rev. Bras. Geoc. 7(2): 102-114.

BRITO NEVES, B.B. \& CORDANI, U. - 1973 - Problemas geocronológicos do Geossinclinal Sergipano e do seu embasamento. In: CONGR. BRAS. GEOL., 27, Aracaju, 1973. Anais. . . Aracaju, SBG, v. 2, p. 67-76.

CHOUVERT, B. - 1969 - Les Guyano-Eburneides de l'Amérique du Sud et de l'Afrique ocidentale. Bull. BRGM. Sect. 4(4): 39-68.

DELTEIL, J.R.; RIVIER, F.; MONTADERT, L.; APOSTOLESW, V.; DIDIER, J.; GOSLIN, M.; PATRIAT, PH. - 1976 - Structure and sedimentation of the Continental Margin, the Gulf of Benin. An. Acad. bras. Ciênc., 48: 51-68.

GORINI, M.A. \& BRYAN, G.M. - 1976 - The tectonic fabric of the Equatorial Atlantic and adjoining continental margins: Gulf of Guinea to Northeastern Brazil. An. Acad. bras. Ciênc., 48: 101-120 [Supi.].
ISLLER, R. - 1977 - Esboço geológico tectônico do Cráton de Guaporé. Rev. Bras, Geoc. 7(3): 177-211.

LASSERE, M. - 1956 - Confirmation de l'existence d une série de granites tertiares du Cameroon. Bull. Rech. Geol. Min., S(3): 141-148.

LEONARDOS, O.H. Jr. \& FYFE, W.S. - 1974 - Ultrametamorphism and melting of a continental margin: The Rio de Janeiro Region. Contr. Mineral Petr., 45: 201-214.

LEONARDOS, O.H. Jr.; FYFE, W.S.; FUCK, R. - 1976 - Panafrican thrusting and melting within the Brazilian continental margin. An. Acad. bras, Cienc., 48: 153-157 [Supl.].

LOCZY, L. de - 1970 - Role of transcurrent faulting in South American Tectonic Framework. AAPG Bull., 54: 2111-2119.

LOCZY, L. de - 1972 - Problemas do Gondwana: Aspectos novos de Gondwana à luz dos eventos diastróficos contemporâneos no Atlântico Sul e nos continentes opostos. Min. Met., 55(328): $137-140$.

LOCZY, L. de - 1976 - Noticia sobre uma sintese estrutural do Arco Transcorrente Tocantins-Araguaia e da margem ocidental da Bacia do Maranháo. Rio de Janeiro - DEGE DRM - Nuclebrás. (Relatório Inédito).

LOCZY, L. de - 1977 - Noticia sobre o "Conceito de origem supergênica do uránio" - sua aplicação na exploração de uránio no Quadrilatero Ferrffero e na area do Serido (Nordeste). Rio de Janeiro DEGE-DRM-Nuclebrás. (Relatório Inédito)

LOCZY, L. de - 1978 - Problemas geotectônicos dos alinhamen. tos arqueozóicos do Cameroon, Pernambuco e Guaporé, com referência d mineralizaçđo de uranto. Rio de Janeiro DEGEDRM-Nuclebrás. Rio (Relatório Inédito). 
SANTOS, E. - 1971 - As feiçðes estruturais da Folha Arcoverde, Pernambuco, e o mecanismo dos falhamentos da "Zona Transversal". Min. Met, $53(313): 35-40$.

SILVA, G.G. da; LIMA, M.I.C.; ANDRADE, A.R.F.; GUIMARÃES, G.; ISSLER, R.S. - 1974 - Geologia das Folhas SB-22, Araguaia e parte de SC-22, Tocantins. In: CONGR. BRAS. GEOL., 28, Porto Alegre, 1974, Anais. . . Porto Alegre, SBG, v. 4, p. 137-141.
TURNER, D.C. - 1967 - Structure of the Jos Plateau, Northern Nigeria. UNESCO/JUGS, Symposium, Montevideo. Paper no 22.

MANUSCRITO

Recebimento em 07 de maio de 1984 Revisăo aceita em 16 de agosto de 1984

\section{IN MEMORIAM}

\section{LOUIS DE LOCZY}

(1897-1980)

"O melhor geólogo é aquele que pisou mais chao", frase dedicatoria de W.D. Johnston Jr., exprime, concisamente, a vida profissional do saudoso Mestre Ludwig Loczy ou Locz, por nós e pelo mundo relembrado como Professor Louis de Loczy.

Nascido em Budapeste a 5 de junho de 1897, seguiu os passos de seu pai, Lajos, notável geólogo do século passado, e terminou sua intensa jornada de trabalho aos 9 de junho de 1980.

O Professor Louis de Loczy, talvez um dos últimos geocientistas ecléticos, pisou, de fato, o chäo - o chão do mundo, desde os extremos do Oriente até estes do Ocidente, usando sua mestria para formar, preparar e orientar geólogos, tanto no ambito prático como no acadêmico.

Membro de várias sociedades e associaģ⿸尸es cient tficas in- ternacionais, teve sua inestimavel contribuição à geologia do Brasil reconhecida ao ser eleito para a Academia Brasileira de Ciências, em 1967, bem como ao ser convidado para se tornar Pesquisador-Conferencista do Conselho Nacional de Pesquisas, em 1968.

A Nuclebrís recebeu do Professor Loczy, enquanto consultor, um acervo de cerca de meia centena de trabalhos versando tanto sobre perspectivas de uránio como sobre analises dos grandes elementos estruturais da Plataforma Brasileira e seu relacionamento com áreas favoráveis à prospeção de urânio.

A imensa vitalidade profissional e a constante atualizasão cientifica que caracterizaram o Mestre, mesmo em tempos adversos, fazem com que a comunidade geologica brasileira o lembre com profundo respeito e carinho. 